\title{
Liposuction for chronic medical diseases and noncosmetic conditions: review of the literature
}

\author{
Hamdy Abuelhassan El-Khatib \\ Department of Plastic and Hand Surgery, Alkhor Hospital, Hamad Medical Corporation, Doha 00974, Qatar.
}

Address for correspondence: Dr. Hamdy Abuelhassan El-Khatib, Department of Plastic and Hand Surgery, Alkhor Hospital, Hamad Medical Corporation, Doha 00974, Qatar. E-mail: hamdya24@yahoo.com

\begin{abstract}
The purpose of this systematic literature review was to evaluate the safety of liposuction techniques and to identify the cosmetic and noncosmetic application of liposuction. Liposuction can be used to improve the quality-of-life in patients with disabling medical conditions in addition to its use for cosmetic rejuvenation. An online search of the Cochrane Library, MEDLINE, Embase, and SciELO were conducted. Forty-seven original articles reported from 1982 to February 2014 were included in this review. The articles reported on the use as well as the limitations of liposuction for treatment of noncosmetic and disabling medical conditions. The criteria used for selection of articles were: large sample size and originality. The case reports were excluded. There was a broad agreement about the applicability and the efficacy of the liposuction for treatment of these chronic medical conditions, such as multiple systemic lipomatosis, dercum's disease, chronic lymphedema, and axillary hyperhidrosis. Literatures review confirmed that Liposuction technique has provided significant and stable cure for these chronic medical conditions. Liposuction is the most frequent esthetic procedure for adipose tissue reduction and treatment of lipedema worldwide. Apart from esthetic indications, liposuction can also be used to treat chronic medical diseases and noncosmetic conditions.
\end{abstract}

Key words:

Liposuction, noncosmetic indications, lipomatosis

\section{INTRODUCTION}

Five thousand years ago, the ancient Egyptian mummification methods were based on removal of all internal organs and subcutaneous fat except the heart, they used the liposuction technique via a small hole to aspirate the whole body contents. ${ }^{[1]}$ The traditional dry liposuction technique was introduced more than 50 years ago. The term liposculpture was introduced by Teimouria and Fisher ${ }^{[2]}$ and Fournier and Otteni ${ }^{[3]}$ who advocated also the criss-cross technique.

\begin{tabular}{|l|l|}
\multicolumn{2}{|c|}{ Access this article online } \\
\hline Quick Response Code: & Website: \\
\hline & www.parjournal.net \\
\cline { 2 - 3 } & \\
\hline
\end{tabular}

Illouz ${ }^{[4]}$ developed the wet tumescent liposuction that helped in standardization and refinement of this technique in 1977. Field, ${ }^{[5]}$ an American dermatologist, started the procedure in USA using the Fischer's suction machine. The first American liposuction course was taught 1982 by Dolsky et al. ${ }^{[6]}$

In 1987, Klein ${ }^{[7]}$ developed a formula of $0.05 \%$ lidocaine, 1:1,000,000 epinephrine, and $10 \mathrm{~mL}$ of bicarbonate and a liter of normal saline. The Klein formula allowed large liposuction to be done under local anesthesia and provided patient a painless $24 \mathrm{~h}$ postoperatively.

Zocchi in $1992,{ }^{[8]}$ presented a revolutionary body contouring technique based using ultrasound energy. This allows selective destruction of lipocytes by means of cavitation and elimination of the fluid fraction (fatty acids). The ultrasound waves stimulate the collagen in deep dermis and initiate lifting of the skin.

In 1992, Apfelberg ${ }^{[9]}$ described the use of laser assisted lipolysis. Laser-assisted liposuction uses laser energy lasers heat the fat, turning it semi-soft and making it 
easier to remove via liposuction, and helps to tighten the skin. There is no scientific evidence demonstrating the advantage of this technique over the ultrasound assisted liposuction or the traditional liposuction.

Blugerman et al. ${ }^{[10]}$ described a novel technique using radiofrequency assisted liposuction. Radio frequency is a form electro-magnetic energy similar to microwave. The process involves passing radio frequency energy through tissue to heat up fat cell and making it easier to remove via liposuction and helps to tighten the skin. This procedure was well-tolerated, safe, and efficient in the removal of a moderate volume of fat. Paul et al. ${ }^{[11]}$ reported three-dimensional skin tightening with this procedure and proposed a mechanism of tissue tightening.

The Water-Jet assisted liposuction is a new technique that uses fan-shaped jet of tumescent solution to anaesthetize the area for liposuction. Sasaki ${ }^{[12]}$ used this technique in 2011 on 41 patients. The amount of instilled tumescent fluid, lidocaine dosage, and aspiration volumes appeared to be safe, with minimal blood loss in small and moderate volume liposuction cases, and have emphasized on efficacy and safety of the technique.

\section{ADIPOSETISSUE DISEASES}

El-Khatib ${ }^{[13]}$ has used the wet technique to treat the lower part of the body with unusual fat distribution that is clinically characterized by massive symmetric and diffuse fat deposition in the trochanters, groins, buttocks, hips, and lower extremities; it contrasts sharply with the normal fat distribution in the upper part of the body. The massive lipomatoses of the lower body can be classified into 3 types: type 1, the familial symmetric lipomatosis (Simon's syndrome) that affects the groins, trochanters, hips, buttocks, and thighs [Figure 1]; type 2, the bilateral peritrochanteric familial lipomatoses [Figure 2]; and type 3, the unilateral peritrochanteric lipomatosis. The adipose tissue diseases are often accompanied by psychological depression due to their disturbed body image. The traditional liposuction is the treatment of choice for these esthetic deformities. The surgical removal of the localized fatty deposit results in unacceptable cosmetic outcome.

\section{MULTIPLE SYSTEMIC LIPOMATOSIS}

Multiple Symmetrical Lipomatosis, also known as benign symmetric lipomatosis or Madelung's disease and Lanois-Bensaude syndrome are metabolic conditions characterized by the growth of fatty masses around the face, back of the head, neck, upper arms, abdomen, back and upper leg in a very specific distribution [Figure 3]. Unlike the usual lipoma, these benign fatty masses are not enclosed in a membranous. Due to this characteristic and symmetrical appearance, these conditions are often dismissed as simple obesity.

Bassetto et al. ${ }^{[14]}$ used the ultrasound-assisted liposuction to treat multiple systemic lipomatosis. He compared the traditional lipectomy and the ultrasound-assisted liposuction and concluded that the ultrasound liposuction

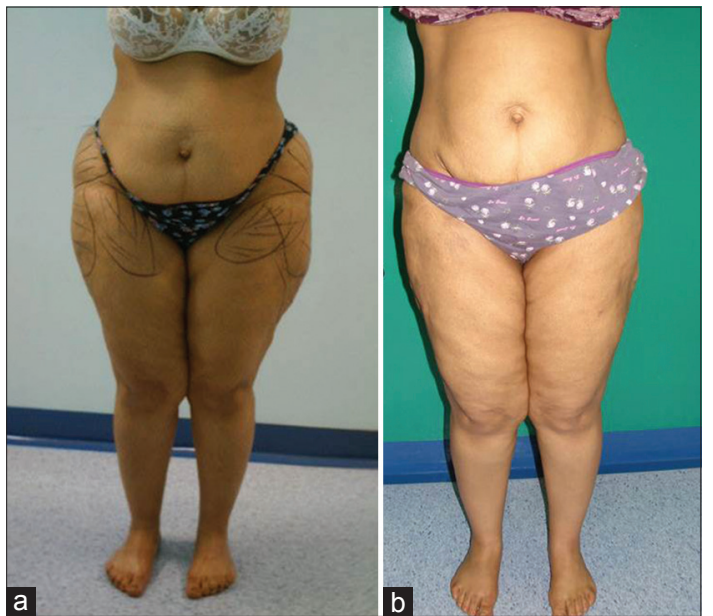

Figure 1: Simon syndrome. (a) Preoperative and (b) one-year postliposuction treatment

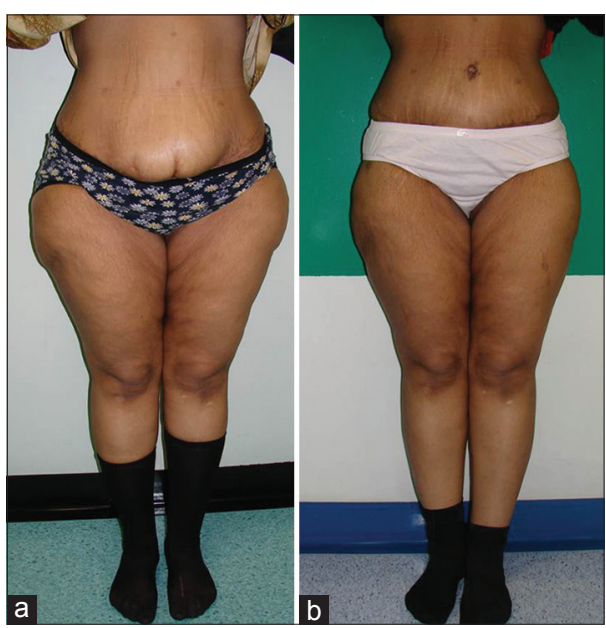

Figure 2: Peritrochantric lipomatosis. (a) Preoperative and (b) 18 months postliposuction

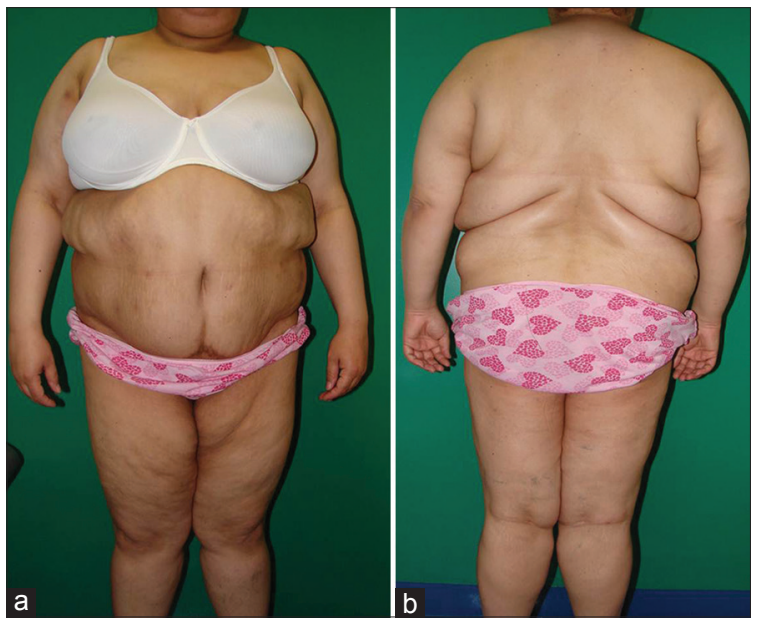

Figure 3: Madelung's disease. (a) Preoperative anterior and (b) posterior photos

is preferable due to a reduction of blood loss and reduction of effort produced by surgeon.

\section{DERCUM'S DISEASE}

Decrum's disease is characterized by the presence of the painful condition, sleep disturbance, memory impairment, 
shortness of breath, constipation, and fatigue. As reported by Hansson et al., Dercum's disease is classified into: generalized diffuse adiposity, generalized nodular adiposity [Figure 4], localized nodular adiposity, and juxta-articular adiposity. ${ }^{[15,16]}$

Hansson traditional treated 53 patients with Dercum's disease that had been operated on with liposuction. As controls, 58 nonoperated subjects with Dercum's disease and 41 obese abdominoplasty patients were followed for 5 years. Hansson suggested that liposuction might alleviate pain in patients with Dercum's disease. However, it is difficult to determine whether the effect is due to the actual surgery or to other factors.

Women are more affected by this condition and, it usually presents in ages between of 30 and 50 years. The differential diagnosis for this condition includes: familial lipomatosis, multiple symmetric lipomatosis, adipose tissue tumors, panniculitis, lipedema, and fibromyalgia. Dercum's disease is diagnosed based on patient's history and the physical findings. There are no specific laboratory tests for this disease.

The treatment strategies for this condition are mostly based on case reports. Treatment of Dercum's disease is usually targeted towards pain relief rather than lipoma removal. ${ }^{[17]}$ Currently, there is a lack of scientific data on the use of integrative therapies for the treatment or prevention of Dercum's disease.

De Silva and Earley ${ }^{[18]}$ used liposuction in the treatment of two patients with juxta-articular adiposis dolorosa (Dercum's disease), and recommended liposuction as an effective, has a low morbidity and is well-tolerated by the elderly.

\section{SUBCUTANEUS LIPOMAS}

A lipoma is a benign tumor composed of adipose tissue. It is the most common benign soft tissue tumor. Lipomas are often soft to the touch, mobile, and painless. Many lipomas are small (under $1 \mathrm{~cm}$ diameter) but can enlarge to sizes greater than $6 \mathrm{~cm}$. They are commonly found in adults from 40 to 60 years of age, but can also be found in younger adults and children.

Al-basti and El-Khatib ${ }^{[19]}$ successfully reported the treatment of subcutaneous capsulated giant (more than $10 \mathrm{~cm}$ diameter) and moderate $(5 \mathrm{~cm}$ to $10 \mathrm{~cm}$ diameter) sized lipomas by traditional liposuction. The capsule was extracted surgically by the end of the procedure from

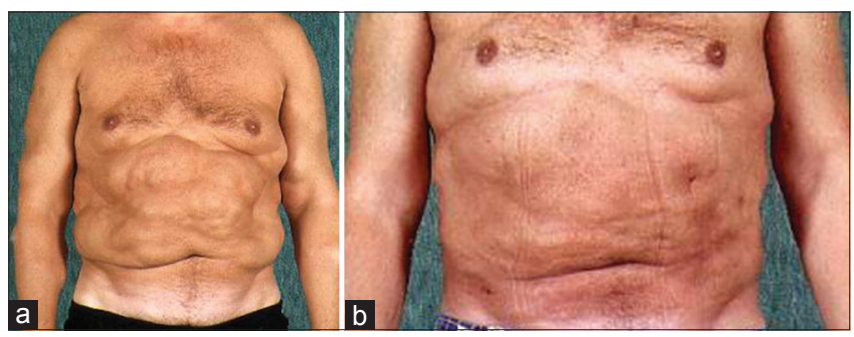

Figure 4: Dercum's disease. (a) Preoperative anterior and (b) 19 months postliposuction the same small incision used for liposuction. There was no recurrence, and the cosmetic outcome was highly satisfactory.

\section{POSTTRAUMATIC LIPOMAS}

The pathogenetic link between soft tissue trauma and formation of lipomas remains controversial. A proposed mechanism is the prolapse of adipose tissue through the fascia defect resulting from direct impact. An alternate explanation is the formation of adipose tissue as a result of preadipocyte differentiation and proliferation mediated by cytokine release following trauma and hematoma formation.

Aust et al. ${ }^{[20]}$ used the simple excision method in 22 cases and used the liposuction method in 1 case and recommend both techniques.

\section{CHRONIC LYMPHEDEMA}

In chronic lymphedema, there is a physiological imbalance of blood flow and lymphatic drainage. The decreased lymphatic drainage results in impaired clearance of lipids and deposition of fat in subcutaneous tissue.

Lymphedema may be inherited (primary) or caused by injury to the lymphatic vessels (secondary). It is most frequently seen after lymph node dissection, surgery, and/ or radiation therapy, most notably in the treatment for breast cancer. In many patients with cancer, this condition does not develop until months or even years after therapy have concluded. Lymphedema may also be associated with trauma or conditions that inhibit the lymphatic system function. In tropical areas, a common cause of secondary lymphedema is filariasis, a parasitic infection. It can also be caused by cellulitis as it compromises lymphatic drainage.

While the exact cause of primary lymphedema is still unknown, it occurs due to poorly developed or missing lymph nodes or channels. Lymphedema may be present at birth, develop at the onset of puberty (praecox), or in adulthood (tarda). Lower-limb primary lymphedema is most common in men, occurring in one or both legs. Secondary lymphedema affects both men and women. In women, it is most prevalent in upper limb after breast cancer surgery and lymph node dissection. It occurs on the same side as surgery. Cancer treatment is the most common cause of secondary lymphedema in western countries. Between $38 \%$ and $89 \%$ of breast cancer patients suffer from lymphedema due to axillary lymph node dissection and/or radiation, ${ }^{[21-23]}$ Unilateral lymphedema occurs in up to $41 \%$ of patients after gynecologic cancer. ${ }^{[24]}$ For men, a 5-66\% incidence of lymphedema has been reported in patients treated with radical removal of lymph glands.

The first report of use of liposuction to reduce the size of lymphedema of the extremity was published by O'Brien et $a .^{[25]}$ and Brorson. ${ }^{[26]}$ Developed a pressure-measuring device to optimize compression treatment of lymphedema 
and evaluation of change in garment pressure with simulated wear and tear, was added to the liposuction technique in order to enhance the outcome.

In 2008, National Institute for Health and Clinical Excellence published guideline on indications and patients' selection for liposuction.

Brorson et al. ${ }^{[27]}$ used absence of pitting, failure of conservative treatment, absence of wounds and cancer as criteria for liposuction for treatment of lymphedema of upper extremity due to ablative surgery for breast cancer.

Literatures review concluded that liposuction demonstrated significant and stable reduction of both upper and lower limbs lymphedema. The technique is also reliable in the treatment of both the acquired and congenital lymphedema.

\section{AXILLARY HYPERHIDROSIS}

Axillary hyperhidrosis, also known as underarm sweating, involves extreme sweat production in the axillary region. This condition is not controlled by deodorants and other odor controlling medication. Axillary hyperhidrosis can occur by itself or associated with hyperhidrosis of other regions of the body.

Over-stimulating of sympathetic nervous system is the main cause of this condition. This has a direct relation to the emotional well-being of the person and environmental stimuli such as stress and anxiety.

Traditional surgical procedure has many disadvantages such as scarring, longer wound healing, complex wound dressing, and limited range of motion for shoulders after surgery.

Seo et al. ${ }^{[28]}$ studied 43 patients who underwent superficial liposuction with curettage for axillary hyperhidrosis and found that 31 patients $(72.1 \%)$ showed excellent to good results. The most common postoperative complication was transient ecchymosis that spontaneously regressed in 1-2 weeks. Focal skin necrosis, induration, and hematoma or seroma were each noted in 4,3 and 1 patient, respectively. All these conditions resolved with proper dressing. The preoperative histological findings included increase in size and number of apocrine glands in cross-section view, and the postoperative specimen showed absence of subcutaneous tissue, including apocrine and eccrine glands, and destruction of sweat glands.

Seo et $a l^{[28]}$ used the tumescent superficial liposuction with curettage of the subdermal tissues for treatment of axillary bromhidrosis and concluded that this technique is an effective and safe.

Ottomann et $a$ al. $^{[29]}$ studied reported a total of 88 patients, 47 patients underwent a tumescent liposuction curettage (TLC) (liposuction combined with curettage), and 41 patients received intradermal Botox injections. The effect of both treatments on the quality-of-life was assessed using a specific hyperhidrosis questionnaire and was correlated with sweat volumes measured by gravimetry. Follow-up after 6 months showed significantly improved sweat volumes of $52 \pm 41 \mathrm{mg} / \mathrm{min}$ of TLC patients versus $78 \pm 87 \mathrm{mg} / \mathrm{min}$ in the Botox group. Ninety-one percent of TLC group and 98\% of Botox group were satisfied with the result. Both methods were superior to the traditional surgical methods in terms of efficacy and complication rates. Both Botox and TLC improved the quality-of-life.

\section{POSTABLATIVE SURGERY}

Use of autologous fat grafting for reconstruction is still controversial because of its safety and efficacy. Liposuction is considered an ideal harvesting method for fat graft [Figure 5].

Coleman ${ }^{[30]}$ advocated a unique method for harvesting fat graft. General anesthesia can be used for removal of large volume of fat although local anesthesia is most commonly used. The preferred donor sites are the abdomen, the inner thigh, the lateral thigh, and the lower back.

Fifteen or twenty-six centimetre two hole Coleman harvesting cannula with a blunt tip and dull distal openings is placed near the end of the cannula, and it is twisted onto a $10 \mathrm{~mL}$ Luer-Lok syringe. The combination of negative pressure and the cannula motion through the fatty tissue allows aspiration of adipose tissue. The recommended centrifugation of the lipoaspirate is 3,000 revolutions per minute for $3 \mathrm{~min}$. The middle layer contains fat cells that can be used as a fat graft.

Another technique is "The one-step harvesting modification" described by Lazzeri et al. ${ }^{[31]}$ It is a useful and time-saving method for high-volume replacement fat graft. This is an atraumatic, low-negative-pressure drain method that helps to preserves any viable lipocytes for transfer. The manual method using a Luer-Lok syringe is also similar and better than the continuous active suction machine liposuction.

Claro et al. ${ }^{[32]}$ studied articles regarding autologous liposuctioned fat grafting of female breast, with a description of clinical complications, radiographic changes, and local breast cancer recurrence.

Claro found that there were few complications reported in the literature; there was no evidence of interference with follow-up for breast cancer posttreatment although oncologic safety remains unclear.

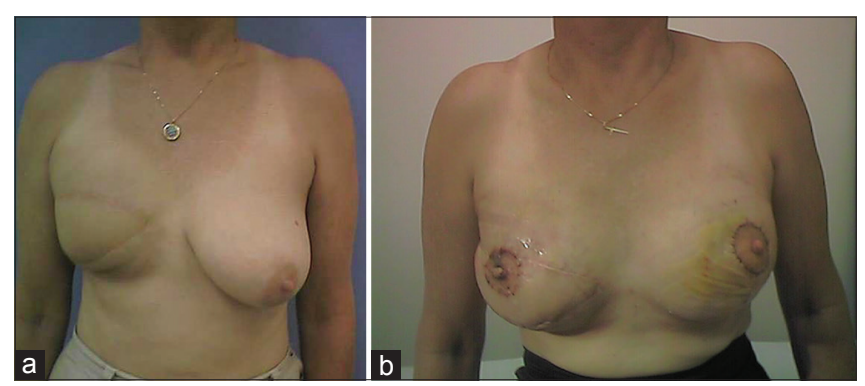

Figure 5: Lipofilling assisted latissimus dorsi flap for right breast reconstruction. (a) Preoperative and (b) two weeks postoperative 


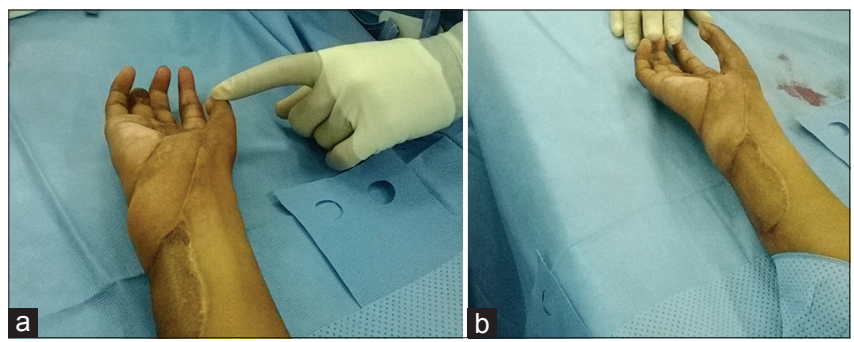

Figure 6: Right-hand reconstruction using perforator muscle skin flap. (a) Six months postoperative and (b) immediate postliposuction images

\section{POSTIRRADIATED SKIN}

Radiation dermatitis results from prolonged exposure of skin to ionizing radiation. ${ }^{[33]}$ It can be seen in patients receiving radiation therapy, with or without adjuvant chemotherapy. ${ }^{[34]}$

Inflammation of the skin after exposure to the radiotherapy (radiodermatitis) can be classified to three specific types of radiodermatitis: acute radiodermatitis, chronic radiodermatitis, and eosinophilic, polymorphic, and pruritic eruption associated with radiotherapy. Radiation therapy can also cause radiation skin cancer.

Radiodermatitis can be successfully treated by implantation of fat graft harvested from liposuction. The lipofilling procedure was first performed by Coleman. ${ }^{\text {[35-37] }}$

After radiation treatment, breast reconstruction with an implant carries a high risk of failure and complication. Clinical and experimental studies have demonstrated that adipose tissue graft (lipofilling) in the irradiated area enhances skin atrophy. Sarfati et $a .^{[38,39]}$ reported the use of lipofilling to the irradiated skin before the implant breast reconstruction. Safarai claimed that the lipofilling will decrease the risk of breast Implant exposure.

\section{DEBULKING OF FLAPS}

Patients often complain about an enlarged or bulky appearance after fasciocutaneus and myocutaneus flap reconstruction.

Conventional liposuction can be used to debulk the skin flap without fear of tissue necrosis [Figure 6].

Single-stage debulking of flaps using suction-assisted lipectomy combined with skin excision is a safe and reliable procedure with results comparable to conventional multistaged surgical techniques. In 2010, Reuben et $a .^{[40]}$ reported on the efficacy and safety of power assisted suction lipectomy for debulking fasciocutaneus flaps in upper and lower extremity. Reuben operated on 16 lower extremity flaps of 15 patients and recommended the use of liposuction as an adjunct in debulking and contouring skin flaps.

Hallock $^{[41-43]}$ reported successful use of traditional liposuction for debulking perforator muscle flaps, and free flaps elsewhere.

Overall, literature review [Table 1] showed good outcomes for suction-assisted lipectomy as an adjuvant procedure
Table 1: Summary of references

\begin{tabular}{|c|c|c|}
\hline Chronic disease & Number of patients & Author \\
\hline \multirow[t]{2}{*}{ Dercum's disease } & 114 & Hansson et al. ${ }^{[16]}$ \\
\hline & 2 & De Silva and Earley ${ }^{[18]}$ \\
\hline $\begin{array}{l}\text { Subcutaneous } \\
\text { lipomas }\end{array}$ & 16 & $\begin{array}{l}\text { Al-Basti and } \\
\text { El-Khatib }^{[19]}\end{array}$ \\
\hline $\begin{array}{l}\text { Posttraumatic } \\
\text { lipomas }\end{array}$ & 23 & Aust et al. ${ }^{[20]}$ \\
\hline \multirow[t]{5}{*}{ Lymphoedema } & 200 & Kissin et al. ${ }^{[22]}$ \\
\hline & 136 & Segerström et al. ${ }^{[23]}$ \\
\hline & 54 & $\begin{array}{l}\text { Werngren-Elgström } \\
\text { and Lidman }\end{array}$ \\
\hline & 134 & O'Brien et al. ${ }^{[25]}$ \\
\hline & $\mathrm{N} / \mathrm{A}$ & Brorson $^{[26]}$ \\
\hline \multirow{2}{*}{$\begin{array}{l}\text { Axillary } \\
\text { hyperhidrosis }\end{array}$} & 88 & Ottomann et al. ${ }^{[29]}$ \\
\hline & 43 & Seo et al. ${ }^{[28]}$ \\
\hline \multirow[t]{3}{*}{$\begin{array}{l}\text { Postablative } \\
\text { reconstruction }\end{array}$} & $\begin{array}{l}\text { An online review of } 60 \\
\text { articles, } 4601 \text { patients }\end{array}$ & Claro Jr et al. ${ }^{[32]}$ \\
\hline & 17 & Coleman $^{[35]}$ \\
\hline & $\mathrm{N} / \mathrm{A}$ & Lazzeri et al. ${ }^{[31]}$ \\
\hline \multirow[t]{2}{*}{ Radiodermatitis } & N/A & Bernier et al. ${ }^{[34]}$ \\
\hline & 68 & Sarfati et al. ${ }^{[38]}$ \\
\hline \multirow[t]{2}{*}{ Debulking of flaps } & 16 flaps in 15 patients & Reuben et al. ${ }^{[40]}$ \\
\hline & 8 flaps in 7 patients & Hallock $^{[41]}$ \\
\hline \multirow{2}{*}{$\begin{array}{l}\text { Multiple systemic- } \\
\text { lipomatosis }\end{array}$} & N/A & Bassetto et al. ${ }^{[14]}$ \\
\hline & & El-Khatib ${ }^{[13]}$ \\
\hline
\end{tabular}

N/A: Not available

for recontouring bulky skin flaps. Most papers recommend debulking three months after initial procedure.

\section{COMPLICATIONS OF LIPOSUCTION}

Severe complications have been reported and include necrotizing fasciitis, ${ }^{[44]}$ toxic shock syndrome, ${ }^{[45]}$ perforation of inner organs, ${ }^{[46]}$ and pulmonary embolism. ${ }^{[47]}$ These complications were mostly due to inappropriate patient selection, use of excessive local anesthesia during mega-liposuction (tumescent technique) and inadequate postoperative surveillance based on literature review, the complication rate usually reflects a lack of medical experience.

Liposuction has gained popularity and has become the most frequent esthetic procedure for adipose tissue reduction and treatment of lipedema. Liposuction is also a suitable treatment for chronic medical conditions like lymphedema, benign adipose tissue diseases, radiodermatitis, re-contouring skin flaps from previous procedures and breast reconstruction. This intervention is not without risks and requires extensive knowledge and training to prevent irreversible medical or esthetic complications.

\section{REFERENCES}

I. Charlotte B. Exploring funerary, beliefs and mummification. In: Charlotte B, editor. The Ancient Egyptians for Dummies. England: John Wiley and Sons; 201 l.p. 189.

2. Teimourian B, Fisher JB. Suction curettage to remove excess fat for body contouring. Plast Reconstr Surg 1981;68:50-8.

3. Fournier PF, Otteni FM. Lipodissection in body sculpturing: the dry procedure. Plast Reconstr Surg 1983;72:598-609. 
4. Illouz YG. History and current concepts of lipoplasty. Clin Plast Surg 1996;23:72I-30.

5. Field LM.The dermatologist and liposuction-a history.J Dermatol Surg Oncol 1987; 13:1040-1.

6. Dolsky RL, Newman J, Fetzek JR, Anderson RW. Liposuction. History, techniques, and complications. Dermatol Clin 1987;5:3।3-33.

7. Klein JA. The tumescent technique. Anesthesia and modified liposuction technique. Dermatol Clin 1990;8:425-37.

8. Zocchi M. Ultrasonic liposculpturing. Aesthetic Plast Surg 1992; 16:287-98.

9. Apfelberg D. Laser-assisted liposuction may benefit surgeons, patients. Clin Laser Mon 1992; 10:193-4

10. Blugerman G, Schavelzon D, Paul MD. A safety and feasibility study of a novel radiofrequency-assisted liposuction technique. Plast Reconstr Surg 2010;125:998-1006.

II. Paul M, Blugerman G, Kreindel M, Mulholland RS. Three-dimensional radiofrequency tissue tightening: a proposed mechanism and applications for body contouring. Aesthetic Plast Surg 201 I;35:87-95.

12. Sasaki GH. Water-assisted liposuction for body contouring and lipoharvesting: safety and efficacy in 4I consecutive patients. Aesthet Surg J 20 I I;3 I:76-88.

13. El-Khatib HA. Unusual distribution of the lower body fatty tissue: classification, treatment, and differential diagnosis. Ann Plast Surg 2008;61:2-8.

14. Bassetto F, Scarpa C, De Stefano F, Busetto L. Surgical treatment of multiple symmetric lipomatosis with ultrasound-assisted liposuction. Ann Plast Surg 20I4;73:559-62.

15. Hansson E, Svensson H, Brorson H. Liposuction may reduce pain in Dercum's disease (adiposis dolorosa). Pain Med 20I I; I2:942-52

16. Hansson E, Svensson H, Brorson H. Review of Dercum's disease and proposal of diagnostic criteria, diagnostic methods, classification and management. Orphanet J Rare Dis 2012;7:23.

17. Lange U, Oelzner P, Uhlemann C. Dercum's disease (Lipomatosis dolorosa): successful therapy with pregabalin and manual lymphatic drainage and a current overview. Rheumatol Int 2008;29:17-22.

18. De Silva M, Earley MJ. Liposuction in the treatment of juxta-articular adiposis dolorosa. Ann Rheum Dis 1990;49:403-4.

19. Al-basti HA, El-Khatib HA. The use of suction-assisted surgical extraction of moderate and large lipomas: long-term follow-up. Aesthetic Plast Surg 2002;26:114-7

20. Aust MC, Spies M, Kall S, Jokuszies A, Gohritz A,Vogt P. Posttraumatic lipoma: fact or fiction? Skinmed 2007;6:266-70.

21. Brorson H, Ohlin K, Olsson G, Svensson B, Svensson H. Controlled compression and liposuction treatment for lower extremity lymphedema. Lymphology 2008;41:52-63.

22. Kissin MW, Querci della Rovere G, Easton D,Westbury G. Risk of lymphoedema following the treatment of breast cancer. Br J Surg 1986;73:580-4.

23. Segerström K, Bjerle P, Graffman S, Nyström A. Factors that influence the incidence of brachial oedema after treatment of breast cancer. Scand J Plast Reconstr Surg Hand Surg 1992;26:223-7.

24. Werngren-Elgström M, Lidman D. Lymphoedema of the lower extremities after surgery and radiotherapy for cancer of the cervix. Scand J Plast Reconstr Surg Hand Surg 1994;28:289-93.

25. O'Brien BM, Mellow CG, Khazanchi RK, Dvir E, Kumar V, Pederson WC. Long-term results after microlymphaticovenous anastomoses for the treatment of obstructive lymphedema. Plast Reconstr Surg 1990;85:562-72.

26. Brorson H. Liposuction in arm lymphedema treatment. Scand J Surg 2003;92:287-95.

27. Brorson H, Hansson E, Jense E, Freccero C. Development of a pressure-measuring device to optimize compression treatment of lymphedema and evaluation of change in garment pressure with simulated wear and tear. Lymphat Res Biol 2012;10:74-80.

28. Seo SH, Jang BS, Oh CK, Kwon KS, Kim MB.Tumescent superficial liposuction with curettage for treatment of axillary bromhidrosis. J Eur Acad Dermatol Venereol 2008;22:30-5.

29. Ottomann C, Blazek J, Hartmann B, Muehlberger T. Liposuction curettage versus Botox for axillary hyperhidrosis. A prospective study of the quality of life. Chirurg 2007;78:356-6I.

30. Coleman SR. Structural fat grafts: the ideal filler? Clin Plast Surg 200 I;28: I I I-9.

31. Lazzeri D, Giannotti G, Colizzi L. One-step fat harvesting method in lipofilling. Plast Reconstr Surg 2009;124:e459-60.

32. Claro FJ, Figueiredo JC, Zampar AG, Pinto-Neto AM. Applicability and safety of autologous fat for reconstruction of the breast. Br J Surg 20I2;99:768-80.

33. William J, Berger T, Elston D. Andrews' diseases of the skin. Clin Dermatol 2005; 10:789-90.

34. Bernier J, Bonner J, Vermorken JB, Bensadoun RJ, Dummer R, Giralt J, Kornek G, Hartley A, Mesia R, Robert C, Segaert S, Ang KK. Consensus guidelines for the management of radiation dermatitis and coexisting acne-like rash in patients receiving radiotherapy plus EGFR inhibitors for the treatment of squamous cell carcinoma of the head and neck. Ann Oncol 2008;19:142-9.

35. Coleman SR. Long-term survival of fat transplants: controlled demonstrations. Clin Plast Surg 1997;2:347-67.

36. Coleman SR. Structural fat grafting: more than a permanent filler. Plast Reconstr Surg 2006; I 1 8:S108-20

37. Coleman SR, Saboeiro AP. Fat grafting to the breast revisited: safety and efficacy. Plast Reconstr Surg 2007; I 1 9:775-85.

38. Sarfati I, Ihrai T, Duvernay A, Nos C, Clough K. Autologous fat grafting to the postmastectomy irradiated chest wall prior to breast implant reconstruction: a series of 68 patients. Ann Chir Plast Esthet 2013;58:35-40.

39. Sarfati I, Ihrai T, Kaufman G, Nos C, Clough KB. Adipose-tissue grafting to the post-mastectomy irradiated chest wall:preparing the ground for implant reconstruction.J Plast Reconstr Aesthet Surg 201 I;64: I I6 I-6.

40. Reuben CM, Bastidas N, Sharma S. Power-assisted suction lipectomy of fasciocutaneous flaps in the extremities. Ann Plast Surg 2010;65:60-5.

4I. Hallock GG. Conventional liposuction-assisted debulking of muscle perforator flaps. Ann Plast Surg 2004;53:39-43.

42. Hallock GG. Liposuction for debulking free flaps. J Reconstr Microsurg 1986;2:235-9.

43. Hallock GG. Defatting of flaps by means of suction-assisted lipectomy. Plast Reconstr Surg 1985;76:948-52

44. Gonzáles Alana I, Marin de la Cruz D, Palao Doménech R, Barret Nerin JP. Necrotizing fasciitis after liposuction. Acta Chir Plast 2007;49:99-I02.

45. Di Candia M, Malata CM. Aesthetic and functional abdominal wall reconstruction after multiple bowel perforations secondary to liposuction. Aesthetic Plast Surg 20I I;35:274-7.

46. Holm C, Mühlbauer W. Toxic shock syndrome in plastic surgery patients: case report and review of the literature. Aesthetic Plast Surg 1998;22:180-4.

47. Zeidman M, Durand P, Kundu N, Doumit G. Fat embolism after liposuction in Klippel-Trenaunay syndrome.J Craniofac Surg 2013;24:1319-21.

How to cite this article: El-Khatib HA. Liposuction for chronic medical diseases and noncosmetic conditions: review of the literature. Plast Aesthet Res 2015;2:1-6.

Source of Support: Nil, Conflict of Interest: None declared.

Received: 20-05-2014; Accepted: 08-10-2014 